\title{
The Endocannabinoid System Tonically Regulates Inhibitory Transmission and Depresses the Effect of Ethanol in Central Amygdala
}

\author{
Marisa Roberto ${ }^{1,2}$, Maureen Cruz', Michal Bajo ${ }^{3}$, George R Siggins ${ }^{3}$, Loren H Parsons ${ }^{1,2}$ \\ and Paul Schweitzer*I \\ 'Committee on the Neurobiology of Addictive Disorders, The Scripps Research Institute, La Jolla, California, USA; ${ }^{2}$ Pearson Center for Alcoholism \\ and Addiction Research, The Scripps Research Institute, La Jolla, California, USA; ${ }^{3}$ Molecular and Integrative Neurosciences Department, \\ The Scripps Research Institute, La Jolla, California, USA
}

\begin{abstract}
The central amygdala ( $\mathrm{CeA}$ ) has a major role in alcohol dependence and reinforcement, and behavioral and neurochemical evidence suggests a role for the endocannabinoid (eCB) system in ethanol binging and dependence. We used a slice preparation to investigate the physiological role of cannabinoids and their interaction with ethanol on inhibitory synaptic transmission in CeA. Superfusion of the

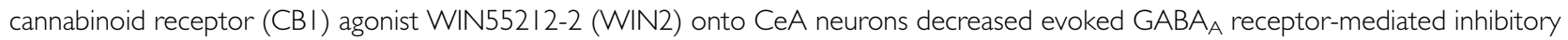
postsynaptic potentials (IPSPS) in a concentration-dependent manner, an effect prevented by the CBI antagonists Rimonabant (SRI4I7I6, SRI) and AM25I. SRI or AM25I applied alone augmented IPSPs, revealing a tonic eCB activity that decreased inhibitory transmission in CeA. Paired-pulse analysis suggested a presynaptic CBI mechanism. Intracellular BAPTA abolished the ability of AM25 I to augment IPSPs, demonstrating the eCB-driven nature and postsynaptic origin of the tonic CBI-dependent control of GABA release. Superfusion of ethanol increased IPSPs and addition of WIN2 reversed the ethanol effect. Similarly, previous superfusion of WIN2 prevented subsequent ethanol effects on GABAergic transmission. The ethanol-induced augmentation of IPSPs was additive to CBI blockade, ruling out a participation of CBI in the action of acute ethanol. Our study points to an important role of CBI in CeA in which the eCBs tonically regulate neuronal activity, and suggests a potent mechanism for modulating CeA tone during challenge with ethanol. Neuropsychopharmacology (2010) 35, 1962-1972; doi:I0.1038/npp.2010.70; published online 12 May 2010
\end{abstract}

Keywords: cannabinoid; alcohol; interaction; synaptic; amygdala; slice

\section{INTRODUCTION}

GABAergic transmission is sensitive to alcohol in several brain structures and is involved in the behavioral actions of alcohol as well as alcohol tolerance and dependence (Siggins et al, 2005; Weiner and Valenzuela, 2006). The amygdaloid complex has a critical role in drug dependence and ethanolreinforcing actions (Davis et al, 1994; Koob et al, 1998), and behavioral studies have implicated GABAergic transmission in the central amygdala (CeA) in the regulation of alcohol intake (Hyytia and Koob, 1995; Koob, 2003). In CeA slices, ethanol increases GABAergic transmission by acting principally at a presynaptic site to augment GABA release (Roberto et al, 2003; Nie et al, 2004).

*Correspondence: Dr P Schweitzer, CNAD_SP30 2400, The Scripps Research Institute, 10550 North Torrey Pines Road, La Jolla, CA 92037, USA, Tel: + I 858784 7258, Fax: + I 8587847393 , E-mail: pschweitzer@scripps.edu

Received 2 December 2009; revised 2I March 20 10; accepted II April 2010
A growing literature points to the endocannabinoid (eCB) system as having a critical role in alcohol drinking and dependence. Administration of a CB1 antagonist reduces alcohol self-administration and preference (Colombo et al, 2005), and mice deficient in CB1 consume less ethanol than do wild-type mice (Wang et al, 2003; Hungund et al, 2003). Conversely, CB1 activation increases ethanol consumption (Colombo et al, 2002). These results point to the involvement of CB1 signaling in some pharmacological actions of alcohol and a possible role for the eCB system in alcohol dependence (Basavarajappa and Hungund, 2005; Colombo et al, 2007). Therefore, the cannabinoid system may constitute part of a brain pathway modulating reinforcement of alcohol consumption, and uncovering the role of $\mathrm{CB} 1$ in the CeA may provide a target for the treatment of alcoholism.

Little information is available on the functional role of CB1 in CeA. In the basolateral amygdala, CB1 ligands act in a retrograde manner to decrease inhibitory transmission, and cannabinoid signaling has been implicated in the extinction of aversive memories (Katona et al, 2001; 
Marsicano et al, 2002; Azad et al, 2003; Zhu and Lovinger, 2005). Several studies have pointed to a physiological role for CB1 in CeA (Patel et al, 2005; Zarrindast et al, 2008), but the only electrophysiological study performed in CeA found no cannabinoid effects on synaptic transmission, and the accompanying immunohistochemical data suggested that CB1 was absent in this nucleus (Katona et al, 2001). Still, other studies found light CB1 staining in CeA (Tsou et al, 1998; McDonald and Mascagni, 2001; Patel et al, 2005), and in situ hybridization methods have detected CB1 mRNAs (Marsicano and Lutz, 1999; Hermann and Lutz, 2005). The presence of CB1 in CeA thus appears likely and mandates further assessment of a physiological role of CB1 in this brain nucleus critical for drug and alcohol dependence.

As ethanol augments GABA responses in CeA neurons and $\mathrm{CB} 1$ ligands are known to decrease GABA transmission, we hypothesize that the eCB system in $\mathrm{CeA}$ regulates the effects of ethanol on synaptic transmission and consequently has a role in alcohol reward and excessive drinking. In this study, we found that cannabinoids act through CB1 to decrease inhibitory transmission at CeA synapses, and CB1 activation prevents ethanol effects on GABA transmission. Our data reveal a key modulatory role of cannabinoids on GABAergic transmission and ethanol effects in CeA.

\section{MATERIALS AND METHODS}

\section{Slice Preparation}

All experimental protocols were consistent with guidelines issued by the National Institutes of Health and were approved by The Scripps Research Institute's Institutional Animal Care and Use Committee. We prepared CeA slices as described previously (Roberto et al, 2003, 2004), from male Sprague-Dawley rats (weighing 120-200 $\mathrm{g}$ ) that were anesthetized with halothane (3\%) and decapitated. In brief, the brains were rapidly removed and placed in ice-cold artificial cerebrospinal fluid (ACSF) gassed with $95 \% \mathrm{O}_{2}$ and $5 \% \mathrm{CO}_{2}$. Transverse slices of $400-\mu \mathrm{m}$ thickness were cut on a Vibratome Series 3000 (Technical Products International, St Louis, MO), incubated in an interface configuration for $\sim 30 \mathrm{~min}$, and then completely submerged and superfused at a constant flow rate of $2-4 \mathrm{ml} / \mathrm{min}$ with warm $\left(31^{\circ} \mathrm{C}\right)$, gassed ACSF of the following composition in $\mathrm{mM}: \mathrm{NaCl}$, 130; KCl, 3.5; $\mathrm{NaH}_{2} \mathrm{PO}_{4}, 1.25 ; \mathrm{MgSO}_{4} 7 \mathrm{H}_{2} \mathrm{O}, 1.5 ; \mathrm{CaCl}_{2}, 2.0$; $\mathrm{NaHCO}_{3}, 24$; glucose, 10 . We added drugs to the ACSF from stock solutions to obtain known concentrations in the superfusate. The inner recording chamber had a total volume of $0.8 \mathrm{ml}$; hence, drug concentrations reached $90 \%$ of the nominal concentration within $2 \mathrm{~min}$.

\section{Recordings}

We recorded neurons principally in the medial subdivision of the CeA with sharp micropipettes filled with $3 \mathrm{M} \mathrm{KCl}$ (impedance range of $60-90 \mathrm{M} \Omega$ ) using the current-clamp mode. We held most neurons near their resting membrane potential (RMP). Data were acquired using an Axoclamp-2 preamplifier (Axon Instruments, Foster City, CA) and stored for later analysis using pClamp software (Axon Instruments). Pharmacologically isolated GABA receptormediated inhibitory postsynaptic currents (IPSPs) were evoked by stimulating locally within the CeA through a bipolar stimulating electrode, while superfusing the slices with the glutamate receptor blockers 6-cyano-7-nitroquinoxaline-2,3-dione (DNQX, 20 $\mu \mathrm{M}$ ) and DL-2-amino-5phosphonovalerate (APV, $30 \mu \mathrm{M})$. We also applied the $\mathrm{GABA}_{\mathrm{B}}$ receptor antagonist CGP 55845A $(1 \mu \mathrm{M})$ to isolate the $\mathrm{GABA}_{\mathrm{A}}$ receptor-mediated component of the IPSP. We often superfused $30 \mu \mathrm{M}$ bicuculline at the end of the experiment to confirm the $\mathrm{GABA}_{\mathrm{A}}$ nature of the IPSP. For whole-cell recordings, patch pipettes were pulled from a borosilicate glass (input resistance 2-3 $\mathrm{M} \Omega$ ) and filled with the following solution (in $\mathrm{mM}$ ): $\mathrm{KMeSO}_{4}$ (70); $\mathrm{KCl}$ (55); $\mathrm{NaCl}(10) ; \mathrm{MgCl}_{2}$ (2); BAPTA (0.1 or 10); $\mathrm{Mg}_{2}$-ATP (3); $\mathrm{Na}_{3}$ GTP (0.3); buffered with $10 \mathrm{mM}$ HEPES, $\mathrm{pH}$ 7.3, osmolarity 275-285.

\section{Electrophysiological Protocols}

To determine the experimental response parameters for each cell, we performed an input-output protocol consisting of a range of current stimulations (typically between 50 and $250 \mathrm{~mA} ; 0.125 \mathrm{~Hz}$ ), starting at the threshold current required to elicit an IPSP up to the strength required to elicit the maximum amplitude. The stimulus strength eliciting $50 \%$ of the maximum response was chosen to conduct experiments and maintained throughout the entire duration of the experiment. The stability of IPSPs was established by stimulating for at least $15 \mathrm{~min}$ before beginning the experiments. The synaptic responses were quantified by averaging two consecutive responses $(30 \mathrm{~s}$ apart, ie, 1 data point per min) and by calculating the IPSP amplitude using the Clampfit software (Axon Instruments). We examined paired-pulse facilitation (PPF), a phenomenon whereby a secondary evoked synaptic response is increased by a preceding primary stimulation of equal intensity (Andreasen and Hablitz, 1994; Bonci and Williams, 1997; Roberto et al, 2003), in each neuron using $100 \mathrm{~ms}$ inter-stimulus intervals; we calculated the pairedpulse ratio as the second IPSP amplitude over that of the first IPSP.

\section{Statistics}

We took all measures before drug superfusion (control), during drug superfusion, and after washout. All values are expressed as mean \pm SEM. We performed statistical analysis using GraphPad Prism version 5.00 (GraphPad Software, San Diego, CA, USA). In the case of a single drug application, we used Student's paired $t$-test. One-way repeated measures ANOVA with Tukey's post hoc test was performed in a multiple drug application. Statistical significance was set at $p<0.05$.

\section{Drugs}

WIN2 (WIN55,212-2; [(3R)-2,3-dihydro-5-methyl-3-(4morpholinylmethyl) pyrrolo [1,2,3-de]-1,4-benzoxazin-6-yl]1-naphthalenyl-methanone, monomethanesulfonate), SR1 (Rimonabant, SR141716; N-(Piperidin-1-yl)-5-(4-iodophenyl)-1-(2,4-dichlorophenyl)-4-methyl-1H-pyrazole-3-carboxamide), and AM251 (N-(Piperidin-1-yl)-5-(4-iodophenyl)1-(2,4-dichloro phenyl)-4-methyl-1H-pyrazole-3-carboxa- 
mide) were dissolved in dimethylsulfoxide (final concentrations of $0.05-0.1 \%$ ), which did not affect the studied synaptic responses in control experiments. WIN2 and AM251 were purchased from Cayman Chemical (Ann Arbor, MI), bicuculline from Tocris-Cookson (Ellisville, MO), and ethanol from Remet (La Mirada, CA). SR1 was obtained from the National Institute of Mental Health's Chemical Synthesis and Drug Supply Program. We purchased all other chemicals from Sigma-Aldrich (St Louis, MO).

\section{RESULTS}

\section{Electrophysiological Properties of the Recorded Neurons}

We recorded intracellularly from CeA neurons using sharp or patch micropipettes and evoked synaptic inhibitory responses by local stimulations through an electrode placed near the recording site, in the medial subdivision of the CeA (Figure 1a). The resulting inhibitory postsynaptic potentials (IPSPs) arose within $2 \mathrm{~ms}$ after electrical stimulation, suggesting activation of monosynaptic connections within the CeA (Figure 1b). The average RMP of our neuronal sample was $-77.5 \pm 0.6 \mathrm{mV}$ when using sharp micropipettes $(n=61)$ and $-70.2 \pm 1.0 \mathrm{mV}$ when using patch micropipettes $(n=23)$.

On the basis of electrophysiological properties, CeA neurons have been identified as type A (little or no spikefrequency accommodation) and type B (showing accommodation) (Schiess et al, 1999; Zhu and Pan, 2004). In our
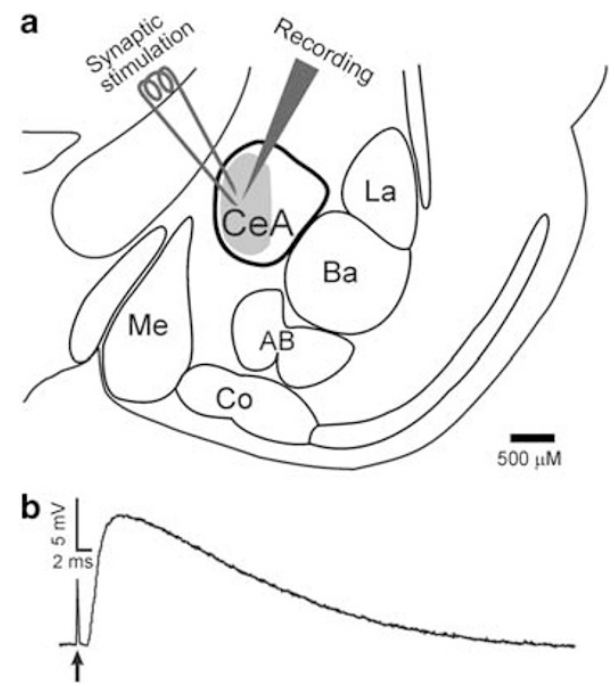

Figure I Synaptic stimulation and recording in the amygdale. (a) Schematic of the amygdala and its related nuclei. The recording electrode was placed in the medial subdivision (gray area) of the central nucleus, and the stimulation electrode used to elicit synaptic responses was placed near the recording site. CeA: central nucleus; La: lateral nucleus; Ba: basal nucleus; AB: accessory basal nucleus; Co: cortical nucleus; Me: medial nucleus (Sah et al, 2003). (b) Representative recording of an IPSP elicited upon delivery of a single electric stimulation (stimulation artifact denoted by arrow). The synaptic response developed $<2 \mathrm{~ms}$ after stimulation, consistent with a monosynaptic response. The superfusate always contained CNQX, APV, and CGP55845A to block AMPA, NMDA, and $\mathrm{GABA}_{B}$ receptors, respectively. experimental conditions, $86 \%$ of the recorded neurons displayed little or no spike-frequency accommodation upon depolarization and could be categorized as type A neurons, equivalent to the $87 \%$ reported by Zhu and Pan (2004). However, in our hands, RMPs were comparable for type A $(-78.0 \pm 0.8 \mathrm{mV})$ and type B $(-75.3 \pm 1.2 \mathrm{mV})$ neurons. On the basis of the profile of the after-hyperpolarization that follows a train of action potentials, we further classified type A neurons as either subtype A1, which presented a medium post-burst after-hyperpolarization, or subtype A2, with a very small or no after-hyperpolarization (Zhu and Pan, 2004). Although a lack of spike-frequency adaptation usually correlates with a limited after-hyperpolarization, we could classify $44 \%$ of type A neurons in subtype A1 and $56 \%$ in subtype A2. These numbers again compare very closely with those reported by Zhu and Pan (2004), 42 and $58 \%$ for $\mathrm{A} 1$ and $\mathrm{A} 2$, respectively, and are also consistent with a previous study from our laboratory (Roberto et al, 2003). We did not observe a significant difference in RMPs between neuronal subtypes $(-77.3 \pm 1.0 \mathrm{mV}$ for type A1, $-78.0 \pm 0.8 \mathrm{mV}$ for type A2). It must be noted that the synaptic responses elicited by local stimulation appeared similar across all neuronal types regardless of firing properties.

\section{The CB1 Agonist WIN2 Decreases Inhibitory Transmission at a Presynaptic Site in CeA}

We first assessed the effect of the potent cannabinoid compound WIN2 on GABAergic transmission. The depressant effect of WIN2 $(2 \mu \mathrm{M})$ developed 4 min after the start of application, reaching a maximum effect after $20 \mathrm{~min}$ of superfusion (Figure 2a and b). On average (mean of 4 points after a steady level was reached and just before change of condition), IPSP amplitudes were significantly decreased to $58 \pm 4 \%$ of control $(n=13, p<0.0001)$. WIN2 $(2 \mu \mathrm{M})$ failed to affect IPSPs only in another two neurons. The WIN2elicited decrease in inhibitory transmission was concentration dependent. We observed no effect of $0.2 \mu \mathrm{M}$ WIN2 ( $99 \pm 4 \%$ of control, $n=4$ ), whereas IPSPs were decreased to $81 \pm 5 \%$ of control with $0.5 \mu \mathrm{M}$ WIN2 $(n=5)$, to $69 \pm 6 \%$ with $1 \mu \mathrm{M}(n=6)$, and $61 \pm 6 \%$ with $5 \mu \mathrm{M}(n=5$; another neuron did not respond). We used a sigmoidal (logistic) fit to analyze the dose-response relationship (Figure 2c). The threshold response of WIN2 was just below $0.2 \mu \mathrm{M}$ and the maximal effect was obtained at $2 \mu \mathrm{M}$, with an apparent EC50 of $0.55 \mu \mathrm{M}$. Thus, WIN2 has a pronounced and consistent effect to decrease inhibitory transmission in CeA.

CB1 ligands are well known to act at presynaptic sites to decrease transmitter release. To determine whether WIN2 acted presynaptically in CeA, we used a PPF protocol of IPSPs evoked by two stimuli of the same intensity delivered $100 \mathrm{~ms}$ apart. At such an interval, the second IPSP (P2) is larger than the first IPSP (P1), and an increase in the pairedpulse ratio (P2/P1) reflects a decrease in transmitter release. Analysis of PPF showed that WIN2 significantly increased the paired-pulse ratio to $136 \pm 6 \%$ of control $(n=10$, $p=0.0003$; Figure $2 \mathrm{~d}$ ), from $1.33 \pm 0.06$ before WIN2 to $1.80 \pm 0.10$ in the presence of the CB1 ligand. These data suggest that WIN2 decreased inhibitory transmission by decreasing the release of GABA at a presynaptic site. 
a

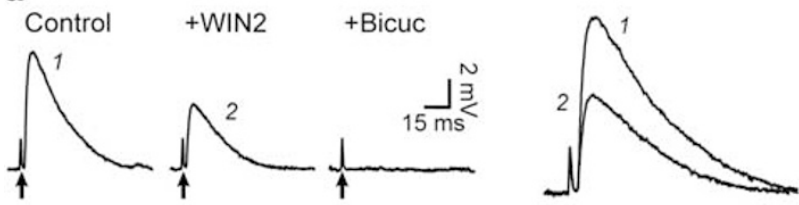

b
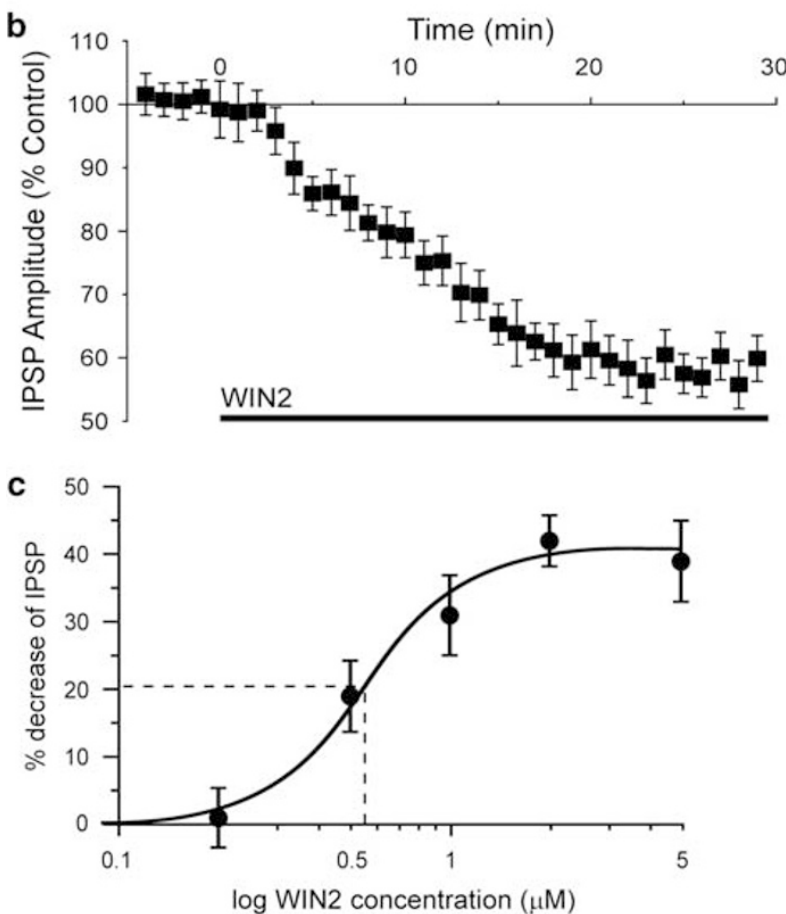

d
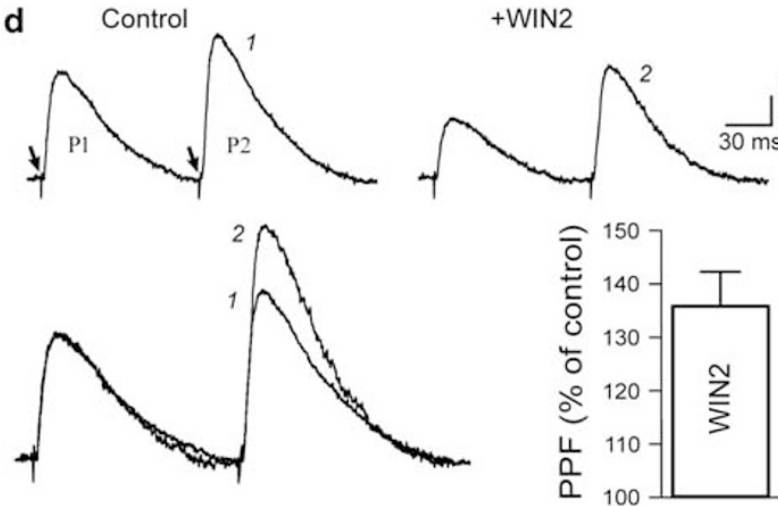

Figure 2 WIN2 decreases GABA $_{A}$-mediated IPSPs in CeA neurons at a presynaptic site. (a) Representative recordings showing IPSPs elicited before (control) and during superfusion of $2 \mu \mathrm{M}$ WIN2 (applied for $25 \mathrm{~min}$ ) in a CeA neuron. The CBI ligand diminished the evoked IPSP. The addition of bicuculline completely obliterated the synaptic response, confirming the $\mathrm{GABA}_{A}$ nature of the IPSP. Recordings were performed at RMP, $-82 \mathrm{mV}$ for this neuron. Stimulus artifact indicated by arrows; traces identified with numbers are magnified and superimposed on the right for comparison. (b) Graph average of IPSP amplitudes over time. WIN2 (application indicated with bar) was added at $t=0$, and the maximum effect was obtained after 20 min of superfusion. (c) Dose-response curve (logistic fit) of the WIN2 effect. WIN2 decreased IPSPs by a maximum of $41 \%$, with an apparent EC50 of $0.55 \mu \mathrm{M}$ (dashed line). (d) Upper panel: with the PPF paradigm, WIN2 $(2 \mu \mathrm{M})$ diminished both IPSPs (PI and P2) but increased the paired-pulse ratio (P2/PI). Arrows indicate stimulation artifact. Lower left: recordings from panel c superimposed and normalized to PI to magnify the increase of PPF. For equivalent PI amplitudes, P2 (identified with numbers) was larger in the presence of WIN2. Lower right: bar graph average depicting the PPF change relative to control condition: $2 \mu \mathrm{M}$ WIN2 increased PPF by $36 \%$.
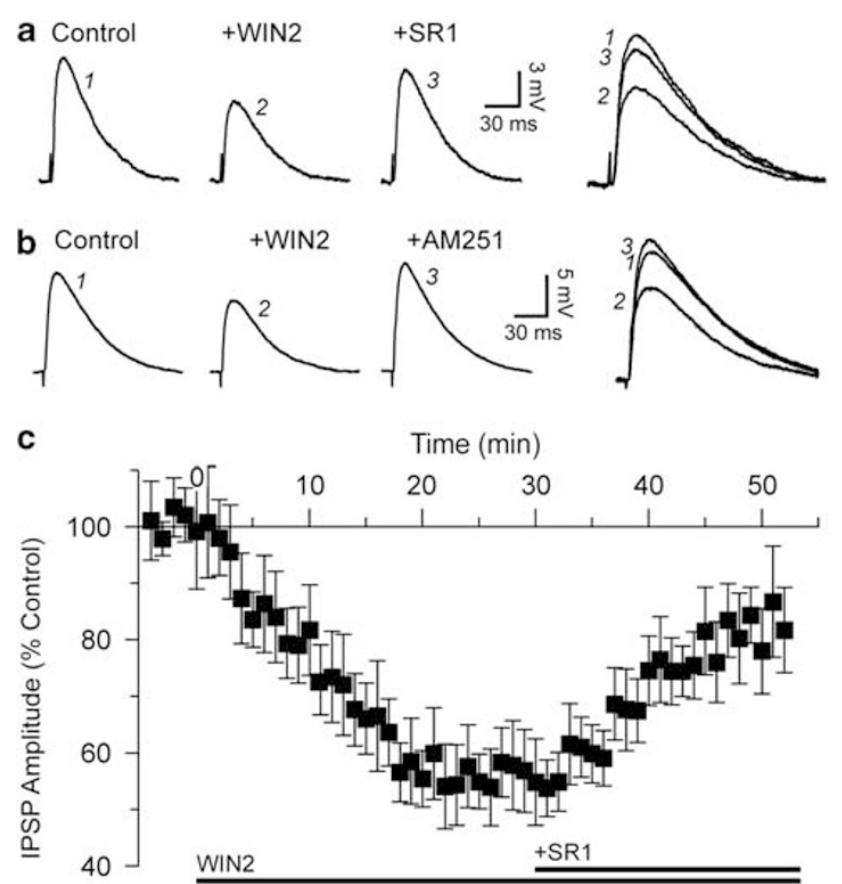

Figure 3 The effect of WIN2 occurs through CBI. (a) The CBI antagonist SRI $(2 \mu \mathrm{M})$ reversed the WIN2-induced IPSP decrease. RMP was $-83 \mathrm{mV}$. (b) Recordings obtained in the whole-cell configuration, using patch pipettes. WIN2 again decreased the IPSP, an effect reversed to about control level by the selective CBI antagonist AM25I ( $2 \mu \mathrm{M})$. RMP was $-70 \mathrm{mV}$. (c) Graph average of six experiments performed using sharp recording electrodes. After a $30 \mathrm{~min}$ exposure to WIN2 that decreased IPSPs to $57 \%$ of control, the CBI antagonist SRI applied for 20 min partly reversed the WIN2 effect with IPSPs returning to $83 \%$ of predrug values.

To verify that WIN2 decreased IPSPs by activating CB1, we used the CB1 antagonists SR1 and AM251. We first applied WIN2 and observed a decrease in IPSPs, and after 30 min of superfusion, we applied SR1 in the continued presence of WIN2. SR1 partially reversed the effect of WIN2 and the IPSP amplitude returned to control levels (Figure 3a). On average, $2 \mu \mathrm{M}$ WIN2 decreased IPSPs to $57 \pm 7 \%$ of control, and subsequent addition of $2 \mu \mathrm{M}$ SR 1 to the superfusate returned the IPSP amplitudes to $83 \pm 6 \%$ of control ( $n=6$; Figure 3c). We obtained similar results with AM251, another CB1 antagonist described as highly selective at CB1 (Figure 3b). Using paired-pulse protocols, we observed an increase in PPF to $143 \pm 12 \%$ of control on exposure to WIN2, and addition of SR1 in the bath reversed PPF values to $109 \pm 8 \%$ of control $(n=5$; not shown), confirming that WIN2 acted at CB1 to decrease GABA release. We conclude that the CB1 ligand WIN2 acts at a presynaptic site to decrease $\mathrm{GABA}_{\mathrm{A}}$ receptor-mediated inhibitory transmission in $\mathrm{CeA}$ neurons, at least in part by activating CB1.

\section{A Tonic eCB Activity in CeA Revealed by Blockade of CB1}

To investigate a possible role of the eCBs in regulating basal transmission in CeA, we treated the slices with the $\mathrm{CB} 1$ antagonist SR1 alone. Superfusion of $2 \mu \mathrm{M}$ SR1 markedly augmented IPSPs recorded at RMP (Figure 4a). On average, $2 \mu \mathrm{M}$ SR1 significantly increased inhibitory transmission to 

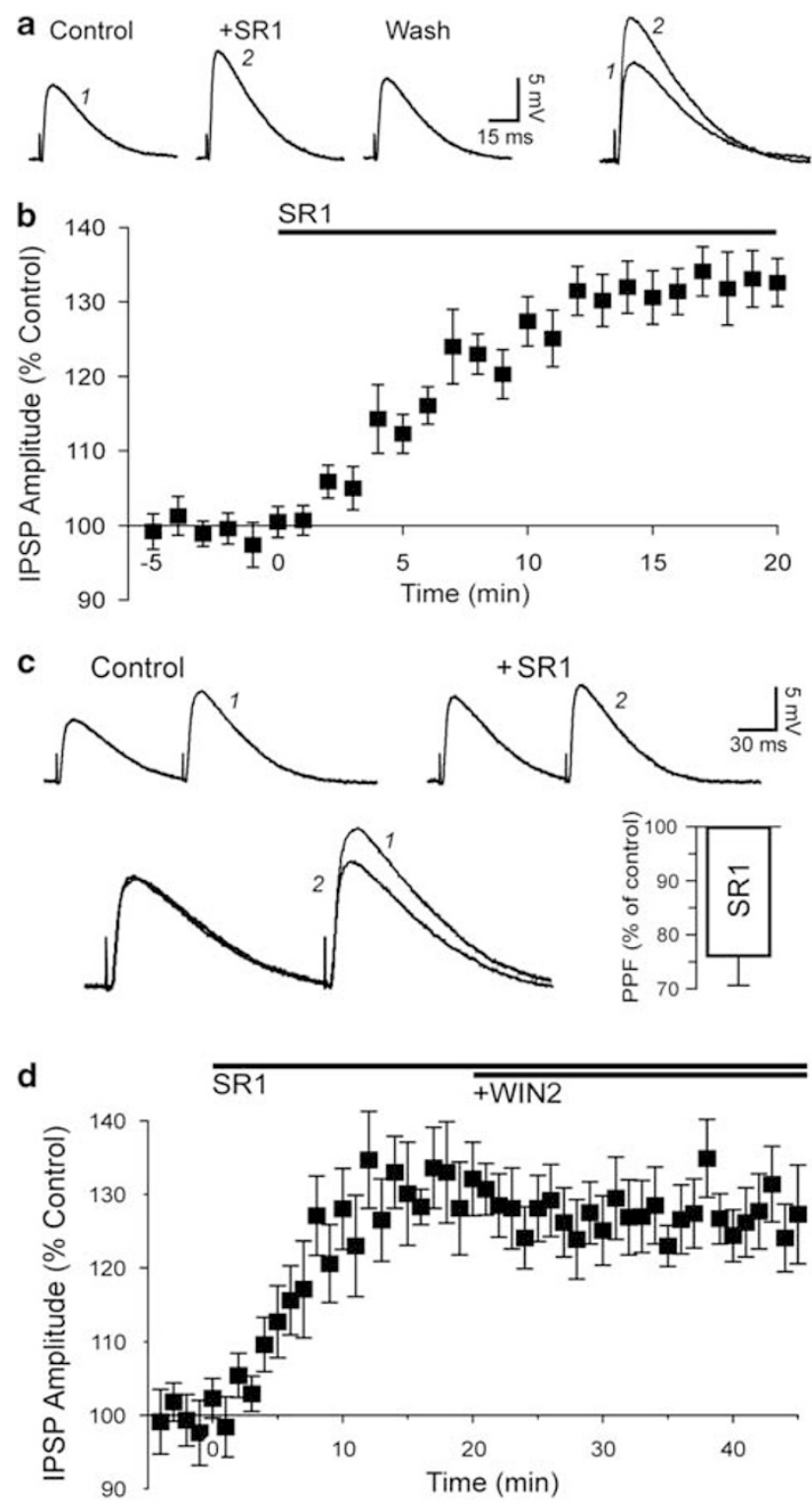

e

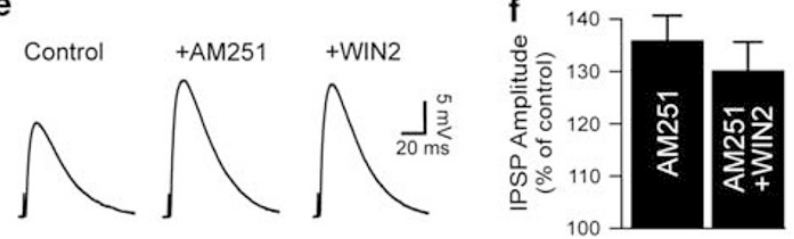

Figure $4 \mathrm{CBI}$ blockade augments IPSPs, showing a tonic eCB activity. (a) In this representative neuron, SRI $(2 \mu \mathrm{M})$ markedly increased IPSP amplitude. RMP was $-79 \mathrm{mV}$. (b) On average, SRI increased inhibitory transmission to $133 \%$ of control. (c) Top: in this CeA neuron, a PPF paradigm showed that SRI increased the first IPSP but had little effect on the second IPSP. Bottom left: traces superimposed and scaled to the first IPSP, magnifying the PPF decrease elicited by SRI. Bottom right: on average, SRI decreased PPF to $76 \%$ of control, indicating a tonic presynaptic effect of eCBs to decrease GABA release. (d) Verification of CBI involvement in the effect of WIN2. SRI (applied at $t=0$ ) increased mean IPSP amplitude to $132 \%$ of control and subsequent application of $2 \mu \mathrm{M}$ WIN2 $(t=20)$ did not affect IPSPs, which remained at $127 \%$ of control, demonstrating that WIN2 decreased IPSPs solely through CBI. (e) AM25I (2 $\mathrm{M}$ ) applied alone increased IPSP amplitude similarly to SRI and prevented the action of $2 \mu \mathrm{M}$ WIN2. RMP was $-72 \mathrm{mV}$. (f) On average, AM25I increased inhibitory transmission to $136 \%$ of control, and the subsequent addition of WIN2 nonsignificantly decreased IPSPs to $130 \%$ of pre-AM25। values.
$133 \pm 4 \%$ of predrug value after $15 \mathrm{~min}$ of application $(n=13, p<0.0001$; Figure 4b). SR1 concomitantly decreased the paired-pulse ratio in a significant manner to $76 \pm 5 \%$ of control value $(p<0.0001$; Figure $4 c)$, indicating increased GABA release upon blockade of CB1. These data suggest that eCBs tonically regulate inhibitory transmission in CeA by decreasing the release of GABA under basal conditions.

As CB1 blockade by itself elicited a marked augmentation of IPSPs but only partially reversed the effect of WIN2, we performed additional experiments to further verify that WIN2 acted solely at CB1. Therefore, we revisited CB1 involvement in the action of WIN2 by testing the cannabinoid in slices pretreated with SR1 or AM251. Addition of $2 \mu \mathrm{M}$ SR1 to the superfusate again increased IPSP amplitudes to $132 \pm 6 \%$ of control, but subsequent addition of $2 \mu \mathrm{M}$ WIN2 in the continued presence of SR1 did not significantly alter IPSP amplitudes, which remained at $127 \pm 6 \%$ of control $(n=6, p>0.05$; Figure $4 \mathrm{~d})$. Consistent with the lack of WIN2 effect on IPSP amplitudes in slices pretreated with SR1, WIN2 did not alter the PPF when applied in the presence of the CB1 antagonist: SR1 decreased the paired-pulse ratio to $77 \pm 6 \%$ of control, a value not significantly altered by the addition of WIN2 (79 $\pm 5 \%$ of control, $p>0.05, n=6$; not shown). We reproduced these results with AM251 (Figure 4e). Upon application of $2 \mu \mathrm{M}$ AM251, IPSPs increased to $136 \pm 5 \%$ of control, and subsequent addition of WIN2 in the continued presence of AM251 nonsignificantly decreased IPSPs to $130 \pm 6 \%$ of control (pre-AM251) values $(n=6, p>0.05$; Figure 4f).

We speculate that the different levels of IPSP amplitudes obtained with SR1 applied alone (above control baseline, Figure 3c) or applied in the presence of WIN (below control baseline, Figure $4 \mathrm{~b}$ ) is due to the disruption of eCB production by WIN2. That is, whereas the activation of CB1 by eCBs is effective in control conditions and suppressed by SR1, after a long application of WIN2, the production of eCBs is affected; hence, the eCB tone is abolished and inhibitory transmission is not augmented beyond control by SR1. We conclude that the decrease in synaptic transmission induced by WIN2 is mediated in full by CB1.

\section{Postsynaptic Calcium Buffering with BAPTA Eliminates Tonic eCB Activity}

Previous studies describing a tonic CB1 activity in brain neurons have pointed to a calcium-dependent postsynaptic formation of eCBs that act in a retrograde manner to decrease transmitter release (Hentges et al, 2005; Neu et al, 2007). To investigate the origin of $\mathrm{eCB}$ activity in CeA, we performed whole-cell recordings with patch pipettes containing the calcium chelator BAPTA to buffer changes in postsynaptic calcium levels believed to contribute to the formation and/or mobilization of the eCBs. In addition, abolishing the effect elicited by the CB1 antagonists would allow us to discriminate between the constitutive activity of CB1 in the absence of ligands (inverse agonist actions of SR1 and AM251) and tonic activity elicited by background levels of eCBs. Accordingly, we recorded CeA neurons in the whole-cell configuration with pipettes containing low 


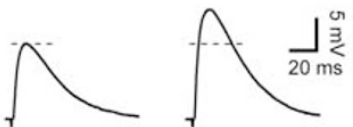

$$
\text { in } 10 \mathrm{mM} B A P T A
$$

Control $\quad+$ AM251

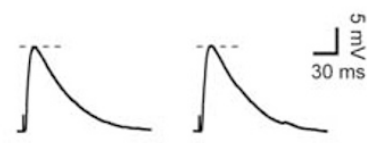

b
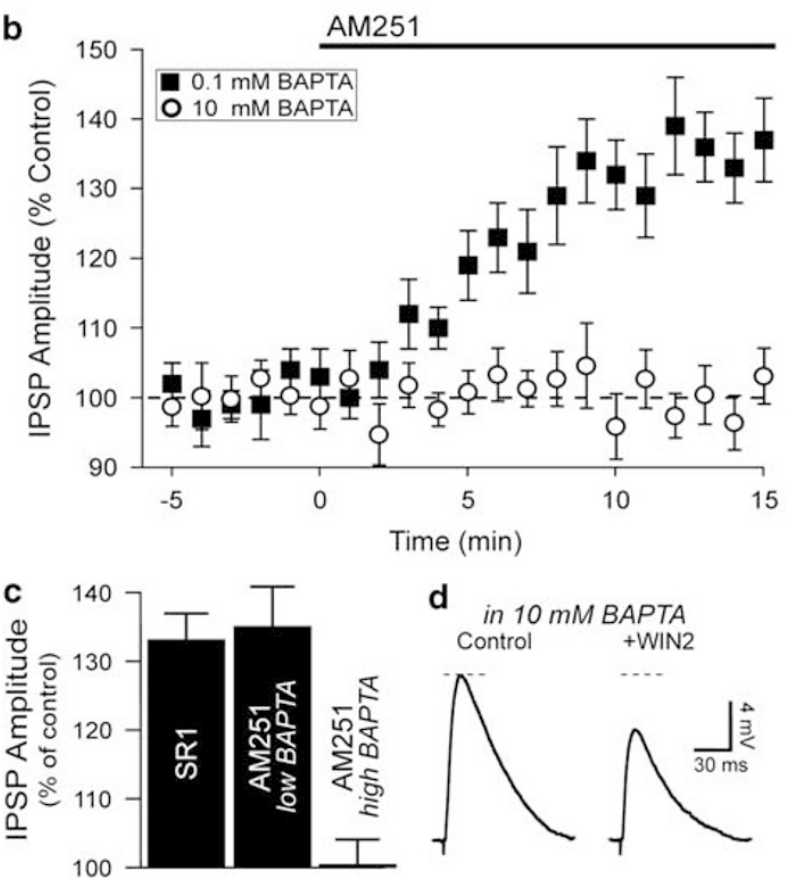

Figure 5 Intracellular calcium buffering with BAPTA eliminates tonic $\mathrm{CBI}$ activity. (a) Whole-cell recordings from CeA neurons using patch pipettes containing BAPTA at low $(0.1 \mathrm{mM}$, control condition) or high ( $10 \mathrm{mM}$, to buffer intracellular calcium) concentrations. The CBI antagonist AM25I ( $2 \mu \mathrm{M})$ increased the IPSP by $45 \%$ when the intracellular recording solution contained low BAPTA (left; RMP was $-71 \mathrm{mV}$ ), whereas a recording solution containing high BAPTA (right; RMP was $-73 \mathrm{mV}$ ) prevented the effect of AM25I. Dotted line is control amplitude. (b) Average time course of the effect of $2 \mu \mathrm{M}$ AM25I on inhibitory transmission in neurons recorded with pipettes containing low or high BAPTA. (c) On average, the effect of SRI on IPSPs was comparable with that of AM25I in neurons recorded in low BAPTA, whereas in neurons loaded with high BAPTA, the effect of AM25I on IPSPs was completely prevented. (d) The inclusion of high BAPTA in the recording pipette did not prevent the WIN2-elicited decrease in inhibitory transmission (RMP was $-69 \mathrm{mV}$ )

(0.1 mM, control) or high (10 mM, to buffer intracellular calcium) concentrations of BAPTA.

In neurons loaded with $0.1 \mathrm{mM}$ BAPTA, a low concentration that does not alter calcium-dependent processes, superfusion of $2 \mu \mathrm{M}$ AM251 increased IPSPs (Figure 5a). However, when recording from neurons loaded with $10 \mathrm{mM}$ BAPTA, the addition of $2 \mu \mathrm{M}$ AM251 in the superfusate failed to increase IPSPs (Figure 5a). On average, AM251 significantly increased the IPSP amplitude to $136 \pm 6 \%$ of control when the recording pipette contained $0.1 \mathrm{mM}$ BAPTA $(n=5, p=0.0001)$, whereas IPSPs were not significantly changed by AM251 when the recording pipette contained $10 \mathrm{mM}$ BAPTA, with the IPSP amplitude remaining at $99 \pm 4 \%$ of control $(n=5, p>0.05$; Figure $5 \mathrm{~b}$ and $\mathrm{c})$. It is noteworthy that the effect of AM251 obtained in low BAPTA was equivalent to that obtained with SR1 (Figure 5c). To ensure that BAPTA did not alter CB1 activation or signaling, we assessed the effect of WIN-2 using recording pipettes containing the calcium chelator. In neurons loaded with $10 \mathrm{mM}$ BAPTA, WIN2 $(2 \mu \mathrm{M})$ decreased IPSPs to $63 \pm 7 \%$ of control ( $n=6$; Figure $5 \mathrm{~d})$, a value comparable with that obtained in control condition. We conclude that CeA neurons locally release eCBs that act in a retrograde manner on presynaptic sites of GABA release. Moreover, these results clearly point to an eCBdriven tonic activation of CB1.

\section{The Effect of Ethanol on GABAergic Transmission in $\mathrm{CeA}$ is Prevented by Activation of CB1}

Ethanol has been shown to increase GABAergic transmission in CeA with a maximally effective concentration of $44 \mathrm{mM}$ (Roberto et al, 2003). We determined the influence of CB1 activation on the ethanol-induced augmentation of IPSPs by first applying ethanol and subsequently adding WIN2 in the continued presence of ethanol. Superfusion of $44 \mathrm{mM}$ ethanol significantly increased IPSP amplitudes to $141 \pm 6 \%$ of control $(n=6, p<0.0001)$, and subsequent addition of $2 \mu \mathrm{M}$ WIN2 together with ethanol significantly decreased IPSP amplitudes to $98 \pm 4 \%$ of control (preethanol) level $(n=6, p<0.0001$; Figure $6 \mathrm{a}$ and b), a $31 \%$ decrease relative to ethanol level (from 141 to 98). The action of WIN2 to reverse the ethanol-induced increase of GABAergic transmission was concentration dependent: in the presence of ethanol, IPSP amplitude was unchanged by $0.2 \mu \mathrm{M}$ WIN2 (from $142 \pm 6 \%$ in ethanol to $145 \pm 7 \% ; n=4$ ), decreased $10 \%$ by $0.5 \mu \mathrm{M}$ WIN2 (from $146 \pm 7 \%$ to $131 \pm 9 \% ; n=4$ ), and decreased $21 \%$ by $1 \mu \mathrm{M}$ WIN2 (from $151 \pm 7 \%$ to $119 \pm 6 \%$; $n=5$ ) (data not shown). PPF analysis indicated that $44 \mathrm{mM}$ ethanol significantly decreased the paired-pulse ratio to $68 \pm 5 \%$ of control $(n=6, p=0.0003)$, confirming the involvement of a presynaptic mechanism in the ethanol-induced increase of GABA transmission. The addition of $2 \mu \mathrm{M}$ WIN2 in the superfusate brought PPF values to $97 \pm 7 \%$ of preethanol levels $(n=6$; Figure $6 c$ ), confirming that ethanol and WIN2 interact presynaptically to modulate GABAergic transmission in CeA.

As the effect of ethanol was reversed by WIN2, we then determined whether previous activation of CB1 would prevent subsequent ethanol effects on GABAergic transmission. Therefore, we applied WIN2, followed by addition of ethanol in the continued presence of WIN2. Superfusion of $2 \mu \mathrm{M}$ WIN2 significantly diminished IPSPs to $60 \pm 5 \%$ of control $(n=7, p=0.0002)$, but subsequent addition of $44 \mathrm{mM}$ ethanol had no significant effect on GABA transmission, with mean IPSP amplitudes remaining at $63 \pm 6 \%$ of pre-WIN2 level ( $n=7, p>0.05$; Figure $7 \mathrm{a}$ and $\mathrm{b}$ ). PPF also remained unchanged upon application of ethanol in the presence of WIN2: WIN2 significantly augmented PPF values to $132 \pm 7 \%(n=7, p=0.0014)$, and PPF was $127 \pm 9 \%$ after addition of ethanol $(n=7, \quad p>0.05$; Figure 7d).

To verify that WIN2 prevented ethanol effects by activating $\mathrm{CB} 1$, in another 7 neurons, we repeated the experiment by adding SR1 after WIN2 but before ethanol (Figure 7c). Superfusion of WIN2 again decreased IPSPs to $57 \pm 7 \%$ of control. Addition of $2 \mu \mathrm{M}$ SR 1 partially reversed this effect with the IPSP amplitude recovering to $84 \pm 7 \%$ of control, consistent with our above data. However, the 

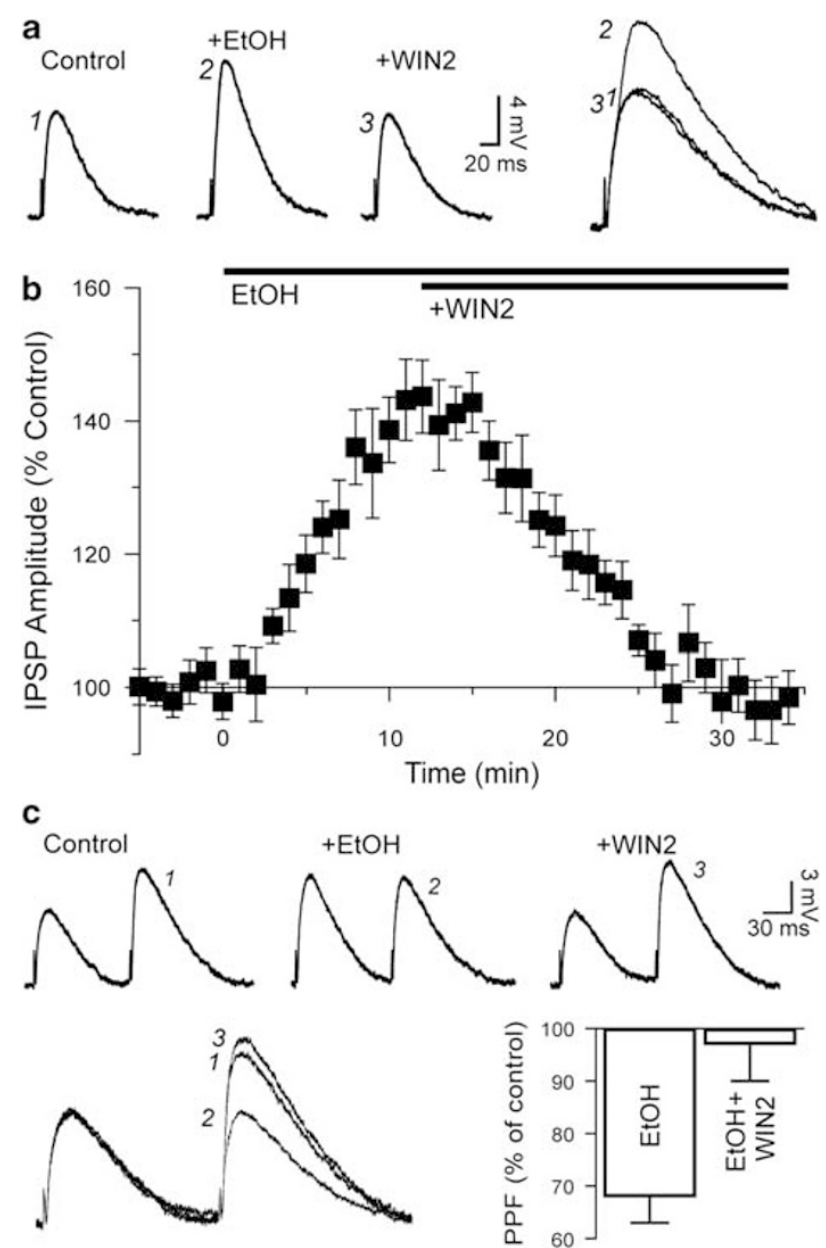

Figure 6 The effect of ethanol on GABA transmission is reversed by WIN2. (a) Superfusion of ethanol $(\mathrm{EtOH})$ onto this representative neuron increased the amplitude of the evoked IPSP. Addition of WIN2 in the continued presence of ethanol completely blocked the effect. RMP was $-77 \mathrm{mV}$. (b) Pooled data showing the reversal of the ethanol effect by WIN2. Ethanol ( $44 \mathrm{mM}, t=0)$ increased IPSP amplitudes to $141 \%$ of control. Subsequent addition of $2 \mu \mathrm{M}$ WIN2 $(t=12)$ brought IPSP amplitudes back to $98 \%$ of preethanol values. (c) Top: recordings obtained using the paired-pulse paradigm. Ethanol increased the primary IPSP but slightly decreased the secondary IPSP, showing a decrease in PPF, an effect completely reversed by WIN2. Bottom left: for scaled PI amplitudes, P2 was much smaller in the presence of ethanol, an effect reversed by the subsequent addition of WIN2. Bottom right: ethanol (44 mM) decreased the mean paired-pulse ratio to $68 \%$ of control, and $2 \mu \mathrm{M}$ WIN2 brought PPF values back to $97 \%$ of preethanol level. The data suggest that ethanol and WIN2 interact at a presynaptic site.

Subsequent addition of $44 \mathrm{mM}$ ethanol in the continued presence of WIN2 and SR1 increased the amplitude of IPSPs to $135 \pm 11 \%$ of pre-WIN2 level. The net ethanol-induced increase of mean IPSP was $51 \%$, an effect comparable with that seen with ethanol alone. PPF analysis showed that SR1 blocked the presynaptic effect of WIN2 to permit the ethanol effect. WIN2 increased PPF values to $139 \pm 10 \%$, and SR1 partially reversed the effect to $109 \pm 9 \%$ of control values, concomitant with the increase in IPSP amplitudes. Addition of ethanol in the continued presence of WIN2 and SR1 decreased PPF values to $73 \pm 12 \%(n=7$; Figure $7 \mathrm{~d})$, an effect comparable with ethanol alone (Figure 6c). We conclude that WIN2 acts at CB1 to completely prevent the

presynaptic action of acute ethanol on GABA transmission in CeA.

\section{CB1 Antagonism does not Impair the Effect of Ethanol on GABAergic Transmission}

We showed that blockade of CB1 by SR1 or AM251 alone augmented IPSP amplitudes, likely by preventing the tonic activity exerted by eCBs on GABA transmission. As the CB1 antagonists and ethanol displayed comparable effects, we sought to determine whether blocking CB1 would affect the ethanol action on GABA transmission. Therefore, we treated the slices with SR1 and subsequently applied ethanol. SR1 
$(2 \mu \mathrm{M})$ alone increased IPSP amplitudes to $134 \pm 5 \%$ of control, and addition of ethanol $(44 \mathrm{mM})$ significantly further increased IPSP amplitudes to $171 \pm 9 \%$ of pre-SR1 levels ( $n=7, p=0.0001$; Figure $8 \mathrm{a}$ and $\mathrm{b})$. The net IPSP augmentation elicited by ethanol in the presence of SR1 was $37 \%$, comparable with ethanol alone (41\%, see Figure $6 \mathrm{~b})$. After washout of SR1 and ethanol, IPSP amplitudes returned near control levels. CB1 blockade and ethanol thus had additive effects in augmenting inhibitory transmission in CeA neurons. PPF analysis indicated that SR1 decreased the paired-pulse ratio to $75 \pm 5 \%$ of control $(n=7)$, and addition of ethanol further decreased the paired-pulse ratio to $57 \pm 7 \%$ of control in a significant manner ( $n=7, p=0.0006$; Figure 8c). SR1 and ethanol thus acted at a presynaptic site to augment GABA transmission in an additive manner. To further ascertain the independence of the respective effects of SR1 and ethanol on inhibitory transmission, we recorded CeA neurons in the whole-cell configuration with patch pipettes containing high BAPTA. As reported above (Figure 5), blockade of CB1 (here with $2 \mu \mathrm{M}$ SR1) did not affect IPSP amplitude in neurons loaded with $10 \mathrm{mM}$ BAPTA. However, subsequent addition of $44 \mathrm{mM}$ ethanol increased IPSP amplitude (Figure 8d), again suggesting that eCBs and ethanol act independently on GABA transmission in CeA. In separate experiments, we also determined that ethanol applied alone (44 mM) increased IPSPs by $49 \pm 6 \%$ in neurons loaded with $10 \mathrm{mM}$ BAPTA (data not shown).

The influence of ethanol on GABA transmission in the various experimental conditions we used is summarized in Figure 8e. Under control conditions, ethanol alone increased IPSP amplitude by $41 \%$. In slices pretreated with the CB1 antagonist SR1, the ethanol effect was unchanged and IPSPs were increased by $37 \%$. The CB1 agonist WIN2 prevented the ethanol effect: superfusion of ethanol in the presence of WIN2 did not alter GABAergic transmission and IPSPs remained at $103 \%$ of preethanol values. Coapplication of SR1 together with WIN2 restored the effect of ethanol, which increased IPSPs by $51 \%$, demonstrating that WIN2 activated CB1 to interfere with the action of ethanol. Finally, in neurons loaded with the calcium chelator BAPTA (10 mM), ethanol normally increased IPSPs by $49 \%$.

\section{DISCUSSION}

Our findings indicate a prominent role for the $\mathrm{eCB}$ system in regulating synaptic transmission in the $\mathrm{CeA}$, a brain nucleus implicated in the etiology of drug and alcohol dependence. Activation of $\mathrm{CB} 1$ completely prevented the ethanol effect on GABA transmission at a presynaptic site, and we uncovered a tonic eCB activity that dampens inhibitory transmission in CeA. However, CB1 antagonism did not interfere with the action of ethanol.

\section{The Activation of CB1 Decreases Inhibitory Synaptic Transmission in the CeA}

We found that WIN2 decreased GABAergic transmission, an effect prevented by SR1 and AM251. Although some studies have indicated that SR1 may also antagonize TRPV1

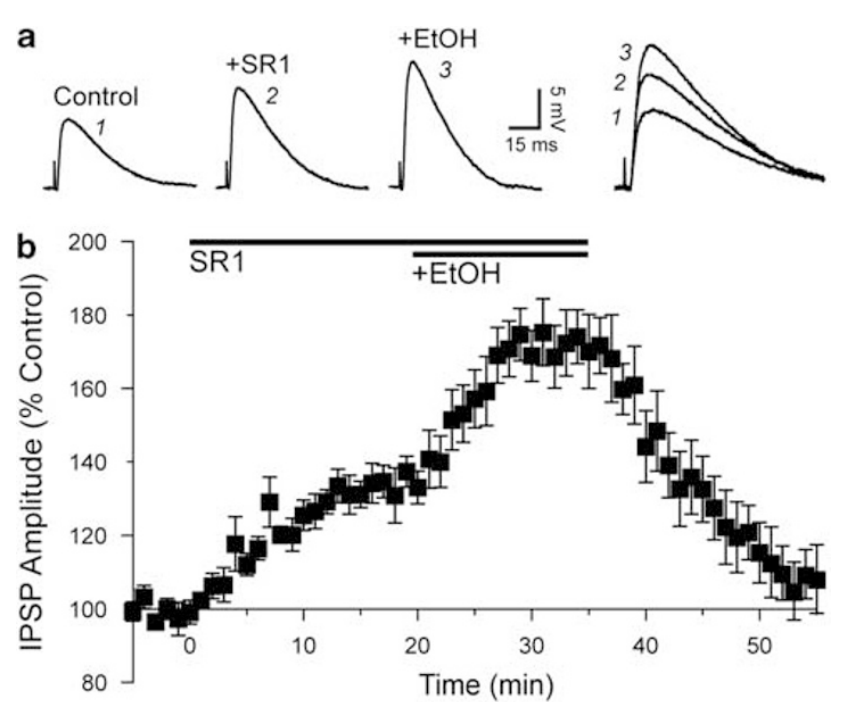

1969

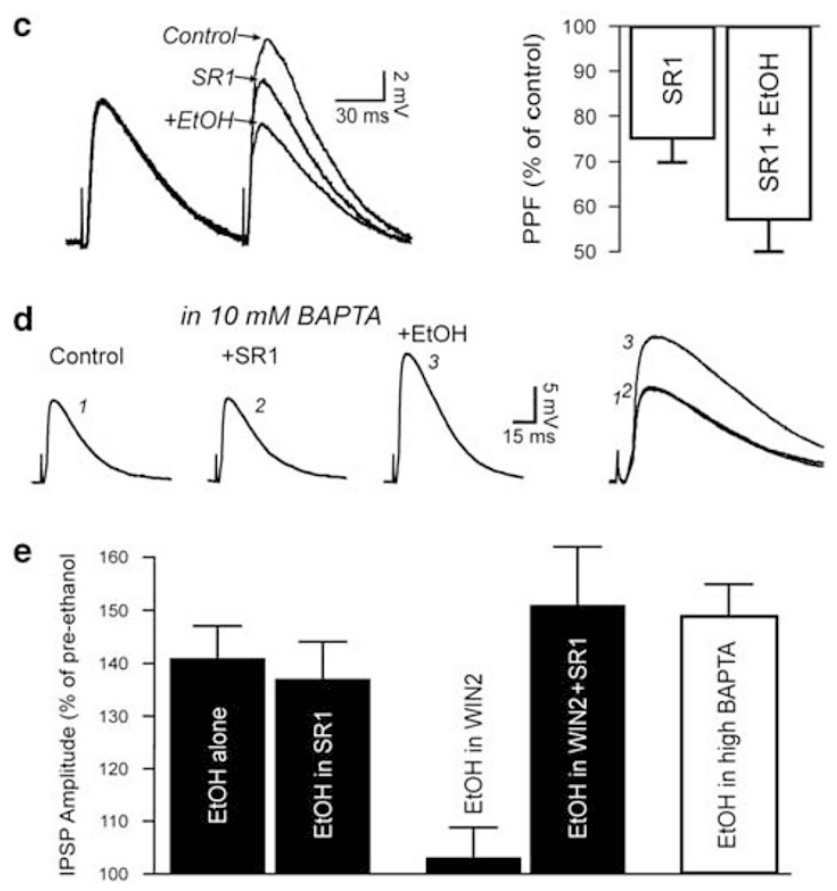

Figure 8 CBI antagonism does not impair the action of ethanol. (a) SRI and ethanol have additive effects on IPSPs. Blockade of CBI with SRI increased the IPSP amplitude, and the subsequent addition of ethanol further increased the IPSP. RMP was $-79 \mathrm{mV}$. (b) Time course of the SRI and ethanol effects $(n=7)$. The effect of ethanol was unaltered by previous blockade of $\mathrm{CBI}$ and developed in a manner similar to that seen in the absence of SRI. On average, SRI $(2 \mu \mathrm{M})$ augmented IPSPs to I34\% of control, and ethanol $(44 \mathrm{mM})$ further increased IPSPs to $171 \%$ of pre-SRI levels. (c) Left: superimposed IPSPs recordings obtained with a paired-pulse protocol. For equivalent PI amplitudes, P2 was decreased by SRI and subsequent addition of ethanol further decreased P2. Right: on average, SRI decreased PPF to $75 \%$ of control and addition of ethanol further decreased PPF to $57 \%$ of control. (d) In this neuron recorded in the wholecell configuration, inclusion of $10 \mathrm{mM}$ BAPTA in the internal solution prevented the effect of $\mathrm{CBI}$ blockade but did not affect the action of ethanol. RMP was $-70 \mathrm{mV}$. (e) Bar graph summarizing the ethanol modulation of GABA transmission in the various experimental conditions used. Ethanol alone increased GABA IPSPs by $41 \%$, an effect unaltered by CBI blockade (37\% in SRI). In the presence of WIN2, ethanol did not alter IPSPs, which remained at I03\% of preethanol value, but SRI completely prevented the action of WIN2 on ethanol, which increased GABA transmission by $51 \%$. Finally, chelation of postsynaptic calcium with high BAPTA did not affect the ethanol effect on GABA IPSPs (49\% increase). 
receptors in addition to $\mathrm{CB} 1, \mathrm{AM} 251$ was shown to be selective for CB1 in those studies (Hájos and Freund, 2002; Pistis et al, 2004; Gibson et al, 2008). Therefore, we conclude that the WIN2 effect we described solely implicates CB1. Our data are in agreement with immunohistochemical findings of light CB1 staining in CeA (Tsou et al, 1998; McDonald and Mascagni, 2001), and apparent low levels of CB1 appear to be sufficient to generate a large physiological response. A similar profile has been observed in the basolateral amygdala and hippocampus where low levels of CB1 immunoreactivity were detected on glutamatergic neurons (and sometimes no immunoreactivity at all), yet robust and widespread CB1 physiological effects were observed in these neurons. Such results underlie the uncertainty of correlating the strength of CB1 staining with that of the physiological response.

CB1 ligands have been shown to diminish inhibitory transmission in the basal and lateral nuclei of the amygdala (Marsicano et al, 2002; Azad et al, 2003), but reportedly had no effect in CeA (Katona et al, 2001), in contrast with our results. We currently have no explanation for this discrepancy, although the use of different internal solutions might influence cannabinoid effects. Almost all neurons we recorded from were responsive to cannabinoid compounds, and the electrophysiological properties of our neuronal sample compare well with those described at large in the CeA (Schiess et al, 1999; Zhu and Pan, 2004), suggesting that our neuronal sample is representative of the overall neuronal population found in the CeA. It could be argued that we stimulated different synaptic afferents, originating outside the $\mathrm{CeA}$, and that cannabinoids activated $\mathrm{CB} 1$ in other amygdaloid nuclei to indirectly influence CeA neurons. However, to elicit synaptic potentials, we placed the stimulation electrode very close to the recording site, away from the medial nucleus and opposite to the basolateral group, and we observed very short response times $(<2 \mathrm{~ms})$ reminiscent of monosynaptic responses triggered by the nearby neurons. The implication of other nuclei is also unlikely because most connections between amygdaloid nuclei are glutamatergic (Sah et al, 2003), and this study involves GABAergic responses.

\section{An eCB Tone Actively Regulates Inhibitory Transmission in CeA}

We observed that $\mathrm{CB} 1$ antagonism augmented inhibitory responses in $\mathrm{CeA}$, suggesting active production of eCBs acting at $\mathrm{CB} 1$ or constitutively active receptors that diminish GABAergic transmission. The augmentation of IPSPs elicited by CB1 antagonism was suppressed by inclusion of high BAPTA in the recording pipette, pointing to an eCB-driven tonic activation of $\mathrm{CB} 1$ rather than an inverse agonist effect of $\mathrm{CB} 1$ antagonists. The results obtained with BAPTA also indicate that CeA neurons release eCBs in response to elevated calcium, and that the tonic inhibition of GABA release is homosynaptically regulated by the postsynaptic neuron. High BAPTA completely abolished the eCB tone, and although the eCBs act as diffusible retrograde messengers and could be released from activated synapses then 'spill over' nearby the recorded neuron, the eCB diffusion may be limited by high-affinity re-uptake in the vicinity of the recorded neuron (Wilson and Nicoll, 2001; Gerdeman et al, 2002). In the hippocampus and hypothalamus, a persistent CB1 activity switches off specific GABAergic neurons, an action attributed to eCB tone (Losonczy et al, 2004; Hentges et al, 2005; Zhu and Lovinger, 2005; Neu et al, 2007). In CeA, behavioral experiments have shown that SR1 treatment or inhibition of eCB degradation affect basal Fos expression, also pointing to a $\mathrm{CB} 1$ tone actively modulating $\mathrm{CeA}$ activity (Patel et al, 2005). We conclude that the basal CB1 activity observed in $\mathrm{CeA}$ is generated by eCBs acting at $\mathrm{CB} 1$ in a persistent manner to dampen inhibitory activity.

CeA activity thus appears to be regulated by ambient levels of eCBs. The CeA is the principal amygdaloid output nucleus and can be described as a gate that regulates the flow of information, consequently influencing the excitability of both local networks and downstream nuclei (Cassell et al, 1999; Sah et al, 2003). The fine-tuning of the GABAergic inhibitory system in $\mathrm{CeA}$ is a prerequisite for controlling the output neurons, and an active $\mathrm{CB} 1$ tone will dampen local GABA release and consequently increase the activity of CeA neurons. Moreover, because CeA projections are mostly GABAergic, tonic $\mathrm{CB} 1$ activity could increase feed-forward inhibition to downstream nuclei. Conversely, administration of a $\mathrm{CB1}$ antagonist in $\mathrm{CeA}$ will increase local inhibition and mute the $\mathrm{CeA}$, consequently relieving inhibition of (disinhibiting) downstream structures. Of course, the net effect of $\mathrm{eCB}$ signaling in a given brain structure is a complex function under the influence of multiple factors (Adermark and Lovinger, 2009), but we predict that $\mathrm{CB} 1$ activation by $\mathrm{eCBs}$ tonically depresses inhibitory transmission in $\mathrm{CeA}$ and increases the outflow of information to downstream structures.

The extended amygdala, a macrostructure comprising the $\mathrm{CeA}$, the bed nucleus of the stria terminalis and a transition area in the shell of the nucleus accumbens, is profoundly implicated in reward processes, and dependence and neuropharmacological studies in animal models of addiction have provided evidence for the dysregulation of specific neurochemical mechanisms in this structure (Koob, 2003). The eCB system is believed to be a key player in the neural basis of addiction (Maldonado et al, 2006; Colombo et al, 2007; Parolaro and Rubino, 2008), and we have shown in this study that the CB1 system tonically influences neuronal activity in the CeA. Such an active CB1 tone has not been observed in the nucleus accumbens or bed nucleus of the stria terminalis (Hoffman and Lupica, 2001; Massi et al, 2008), or in the amygdalar basal and lateral nuclei that project to the CeA (Marsicano et al, 2002; Azad et al, 2003). Thus, only the CeA is under the active regulation of the CB1 system in the extended amygdala, and the modification of this eCB tone by substances of abuse such as alcohol may emerge as a neuroadaptive cellular mechanism involved in the development of alcoholism and drug addiction.

\section{Reciprocal Regulation of GABAergic Transmission by Ethanol and eCBs}

Ethanol and WIN2 had opposite actions on GABAergic transmission at the presynaptic level. WIN2 diminished GABA transmission and blocked the ethanol effect in a CB1sensitive manner, indicating that $\mathrm{CB} 1$ interferes with alcohol effects and is preemptive over the action of ethanol 
in CeA neurons. WIN2 also depressed alcohol effects in the nucleus accumbens in vivo (Perra et al, 2005) and prevented the ethanol-induced increase of GABA release in cerebellar slices (Kelm et al, 2008), consistent with our results. WIN2 is among the most potent CB1 agonists and its effects are much more pronounced than those of AEA or 2-AG on synaptic activity (Bajo et al, 2009). Thus, the physiological alteration of alcohol effects by eCBs in CeA is likely to be modulatory instead of preventive, and the effects of ethanol could be amplified or lessened according to ambient eCB levels at the time of alcohol consumption.

SR1 treatment prevents the in vivo electrophysiological effects of ethanol in the ventral tegmental area, nucleus accumbens, and basolateral amygdala (Perra et al, 2005, 2008), and SR1 reverses the ethanol-induced depression of excitatory transmission in cultured hippocampal neurons (Basavarajappa et al, 2008). Therefore, it could be hypothesized that ethanol increases GABA transmission by interfering with the eCB system, for example, by decreasing the $\mathrm{eCB}$ tone and consequently disinhibiting GABA transmission. However, we found that ethanol and CB1 blockade increased GABA transmission in an additive manner, indicating that $\mathrm{CB} 1$ does not mediate the effect of ethanol in CeA. In addition, ethanol increased GABAergic transmission in neurons loaded with BAPTA to suppress the effect of CB1 blockade, further confirming that ethanol actions do not implicate the eCBs in CeA.

The exact presynaptic mechanisms affected by ethanol and cannabinoids to alter GABA release remain to be determined. $\mathrm{CB} 1$ and ethanol may act on common signaling pathways to regulate the release of GABA, as suggested in the cerebellum where activation of presynaptic protein kinase A (PKA) is necessary for the ethanol-induced increase in spontaneous GABA release (Kelm et al, 2008). CB1 activation is well known to inhibit adenylate cyclase and decrease PKA activity, and the mechanism of the cannabinoid-induced decrease of spontaneous GABA release in cerebellar neurons seems to involve PKA (Kelm et al, 2008). Therefore, the adenylate cyclase/PKA pathway may be a common signal transduction pathway targeted in opposite ways by $\mathrm{eCBs}$ and ethanol to regulate GABA release. Another potential candidate is protein kinase $\mathrm{C}$ epsilon (PKC $\varepsilon$ ). We recently determined that a PKC $\varepsilon$ signaling pathway is activated by ethanol to augment GABA release in CeA (Bajo et al, 2008). PKC $\varepsilon$ reportedly negatively regulates the affinity of WIN2 at CB1 (Wallace et al, 2009), although a possible modulation of $\mathrm{eCB}$ activity at $\mathrm{CB} 1$ by PKC $\varepsilon$ is uncertain. Nonetheless, these two kinases seem to be interesting candidates to participate in the opposite regulation of GABA release by ethanol and $\mathrm{eCBs}$, and a combined crosstalk between PKA and PKC $\varepsilon$ to regulate ethanol and eCB effects is also possible (Kelm et al, 2008).

\section{Conclusions}

The eCB system and CB1 have emerged as promising targets for medications to treat alcohol and drug dependence. We showed in this study that cannabinoids act at CB1 in CeA neurons to decrease inhibitory transmission and interfere with the physiological effects of ethanol. We also uncovered an eCB tone that influences neuronal activity in the CeA, a brain structure that has a major role in alcohol dependence and reinforcement. Further studies to delineate the cellular effects of eCBs and CB1 ligands and their modulation by acute and chronic alcohol treatment may lead to a better understanding of the cellular mechanisms of addiction and dependence.

\section{ACKNOWLEDGEMENTS}

This work was supported by the National Institutes of Health funding from NIAAA (AA06420, AA007456, AA014619, AA016985, A013498, AA015566). We thank the Helen Doris Research Center, Samuel Madamba for technical support, and George Koob for helpful discussions. This is publication number 20070 from The Scripps Research Institute.

\section{DISCLOSURE}

The authors declare no conflict of interest.

\section{REFERENCES}

Adermark L, Lovinger DM (2009). Frequency-dependent inversion of net striatal output by endocannabinoid-dependent plasticity at different synaptic inputs. J Neurosci 29: 1375-1380.

Andreasen M, Hablitz JJ (1994). Paired-pulse facilitation in the dentate gyrus: a patch-clamp study in rat hippocampus in vitro. J Neurophysiol 72: 326-336.

Azad SC, Eder M, Marsicano G, Lutz B, Zieglgänsberger W, Rammes G (2003). Activation of the cannabinoid receptor type 1 decreases glutamatergic and GABAergic synaptic transmission in the lateral amygdala of the mouse. Learn Mem 10: 116-128.

Bajo M, Cruz MT, Siggins GR, Messing RO, Roberto M (2008). Protein kinase Ce mediation of CRF- and ethanol-induced GABA release in central amygdala. Proc Natl Acad Sci USA 105: 8410-8415.

Bajo M, Roberto M, Schweitzer P (2009). Differential alteration of hippocampal excitatory synaptic transmission by cannabinoid ligands. J Neurosci Res 87: 766-775.

Basavarajappa BS, Hungund BL (2005). Role of the endocannabinoid system in the development of tolerance to alcohol. Alcohol Alcohol 40: 15-24.

Basavarajappa BS, Ninan I, Arancio O (2008). Acute ethanol suppresses glutamatergic neurotransmission through endocannabinoids in hippocampal neurons. $J$ Neurochem 107: 1001-1013.

Bonci A, Williams JT (1997). Increased probability of GABA release during withdrawal from morphine. J Neurosci 17: 796-803.

Cassell MD, Freedman LJ, Shi C (1999). The intrinsic organization of the central extended amygdala. Ann N Y Acad Sci 877: 217-241.

Colombo G, Orru A, Lai P, Cabras C, Maccioni P, Rubio M et al (2007). The cannabinoid CB1 receptor antagonist, rimonabant, as a promising pharmacotherapy for alcohol dependence: preclinical evidence. Mol Neurobiol 36: 102-112.

Colombo G, Serra S, Brunetti G, Gomez R, Melis S, Vacca G et al (2002). Stimulation of voluntary ethanol intake by cannabinoid receptor agonists in ethanol-preferring sP rats. Psychopharmacology (Berl) 159: 181-187.

Colombo G, Serra S, Vacca G, Carai MAM, Gessa GL (2005). Endocannabinoid system and alcohol addiction: pharmacological studies. Pharmacol Biochem Behav 81: 369-380.

Davis M, Rainnie DG, Cassell MD (1994). Neurotransmission in the rat amygdala related to fear and anxiety. Trends Neurosci 17: 208-214. 
Gerdeman GL, Ronesi J, Lovinger DM (2002). Postsynaptic endocannabinoid release is critical to long-term depression in the striatum. Nat Neurosci 5: 446-451.

Gibson HE, Edwards JG, Page RS, Van Hook MJ, Kauer JA (2008). TRPV1 channels mediate long-term depression at synapses on hippocampal interneurons. Neuron 57: 746-759.

Hájos N, Freund TF (2002). Pharmacological separation of cannabinoid sensitive receptors on hippocampal excitatory and inhibitory fibers. Neuropharmacology 43: 503-510.

Hentges ST, Low MJ, Williams JT (2005). Differential regulation of synaptic inputs by constitutively released endocannabinoids and exogenous cannabinoids. J Neurosci 25: 9746-9751.

Hermann H, Lutz B (2005). Coexpression of the cannabinoid receptor type 1 with the corticotropin-releasing hormone receptor type 1 in distinct regions of the adult mouse forebrain. Neurosci Lett 375: 13-18.

Hoffman AF, Lupica CR (2001). Direct actions of cannabinoids on synaptic transmission in the nucleus accumbens: a comparison with opioids. J Neurophysiol 85: 72-83.

Hungund BL, Szakall I, Adam A, Basavarajappa BS, Vadasz C (2003). Cannabinoid CB1 receptor knockout mice exhibit markedly reduced voluntary alcohol consumption and lack alcohol-induced dopamine release in the nucleus accumbens. J Neurochem 84: 698-704.

Hyytia P, Koob GF (1995). GABAA receptor antagonism in the extended amygdala decreases ethanol self-administration in rats. Eur J Pharmacol 283: 151-159.

Katona I, Rancz EA, Acsády L, Ledent C, Mackie K, Hájos N et al (2001). Distribution of CB1 cannabinoid receptors in the amygdala and their role in the control of GABAergic transmission. J Neurosci 21: 9506-9518.

Kelm MK, Criswell HE, Breese GR (2008). The role of protein kinase $\mathrm{A}$ in the ethanol-induced increase in spontaneous GABA release onto cerebellar Purkinje neurons. J Neurophysiol 100: 3417-3428.

Koob GF (2003). Neuroadaptive mechanisms of addiction: studies on the extended amygdala. Eur Neuropsychopharmacol 13: $442-452$.

Koob GF, Roberts AJ, Schulteis G, Parsons LH, Heyser CJ, Hyytia P et al (1998). Neurocircuitry targets in ethanol reward and dependence. Alcohol Clin Exp Res 22: 3-9.

Losonczy A, Biró AA, Nusser Z (2004). Persistently active cannabinoid receptors mute a subpopulation of hippocampal interneurons. Proc Natl Acad Sci USA 101: 1362-1367.

Maldonado R, Valverde O, Berrendero F (2006). Involvement of the endocannabinoid system in drug addiction. Trends Neurosci 29: $225-232$.

Marsicano G, Lutz B (1999). Expression of the cannabinoid receptor $\mathrm{CB} 1$ in distinct neuronal subpopulations in the adult mouse forebrain. Eur J Neurosci 11: 4213-4225.

Marsicano G, Wotjak CT, Azad SC, Bisogno T, Rammes G, Cascio MG et al (2002). The endogenous cannabinoid system controls extinction of aversive memories. Nature 418: 530-534.

Massi L, Elezgarai I, Puente N, Reguero L, Grandes P, Manzoni OJ et al (2008). Cannabinoid receptors in the bed nucleus of the stria terminalis control cortical excitation of midbrain dopamine cells in vivo. J Neurosci 28: 10496-10508.

McDonald AJ, Mascagni F (2001). Localization of the CB1 type cannabinoid receptor in the rat basolateral amygdala: high concentrations in a subpopulation of cholecystokinin-containing interneurons. Neuroscience 107: 641-652.

Neu A, Foldy C, Soltesz I (2007). Postsynaptic origin of CB1dependent tonic inhibition of GABA release at cholecystokinin- positive basket cell to pyramidal cell synapses in the CA1 region of the rat hippocampus. J Physiol 578: 233-247.

Nie ZG, Schweitzer P, Roberts AJ, Madamba SG, Moore SD, Siggins GR (2004). Ethanol augments GABAergic transmission in the central amygdala via CRF1 receptors. Science 303: 1512-1514.

Parolaro D, Rubino T (2008). The role of the endogenous cannabinoid system in drug addiction. Drug News Perspect 21: 149-157.

Patel S, Cravatt BF, Hillard CJ (2005). Synergistic interactions between cannabinoids and environmental stress in the activation of the central amygdala. Neuropsychopharmacology 30: 497-507.

Perra S, Pillolla G, Luchicchi A, Pistis M (2008). Alcohol inhibits spontaneous activity of basolateral amygdala projection neurons in the rat: involvement of the endocannabinoid system. Alcohol Clin Exp Res 32: 443-449.

Perra S, Pillolla G, Melis M, Muntoni AL, Gessa GL, Pistis M (2005). Involvement of the endogenous cannabinoid system in the effects of alcohol in the mesolimbic reward circuit: electrophysiological evidence in vivo. Psychopharmacology 183: 368-377.

Pistis M, Perra S, Pillolla G, Melis M, Gessa GL, Muntoni AL (2004). Cannabinoids modulate neuronal firing in the rat basolateral amygdala: evidence for CB1-and non-CB1-mediated actions. Neuropharmacology 46: 115-125.

Roberto M, Madamba SG, Moore SD, Tallent MK, Siggins GR (2003). Ethanol increases GABAergic transmission at both preand postsynaptic sites in rat central amygdala neurons. Proc Natl Acad Sci USA 100: 2053-2058.

Roberto M, Madamba SG, Stouffer DG, Parsons LH, Siggins GR (2004). Increased GABA release in the central amygdala of ethanol-dependent rats. J Neurosci 24: 10159-10166.

Sah P, Faber ES, Lopez de AM, Power J (2003). The amygdaloid complex: anatomy and physiology. Physiol Rev 83: 803-834.

Schiess MC, Callahan PM, Zheng H (1999). Characterization of the electrophysiological and morphological properties of rat central amygdala neurons in vitro. J Neurosci Res 58: 663-673.

Siggins GR, Roberto M, Nie Z (2005). The tipsy terminal: presynaptic effects of ethanol. Pharmacol Ther 107: 80-98.

Tsou K, Brown S, Sañudo-Peña MC, Mackie K, Walker JM (1998). Immunohistochemical distribution of cannabinoid CB1 receptors in the rat central nervous system. Neuroscience 83: 393-411.

Wallace MJ, Newton PM, McMahon T, Connolly J, Huibers A, Whistler J et al (2009). PKCe regulates behavioral sensitivity, binding and tolerance to the CB1 receptor agonist WIN55,212-2. Neuropsychopharmacology 34: 1733-1742.

Wang L, Liu H, Harvey-White J, Zimmer A, Kunos G (2003). Endocannabinoid signaling via cannabinoid receptor 1 is involved in ethanol preference and its age-dependent decline in mice. Proc Natl Acad Sci USA 100: 1393-1398.

Weiner JL, Valenzuela CF (2006). Ethanol modulation of GABAergic transmission: the view from the slice. Pharmacol Ther 111: 533-554.

Wilson RI, Nicoll RA (2001). Endogenous cannabinoids mediate retrograde signalling at hippocampal synapses. Nature 410: 588-592.

Zarrindast MR, Sarahroodi S, Arzi A, Khodayar MJ, TaheriShalmani S, Rezayof A (2008). Cannabinoid CB1 receptors of the rat central amygdala mediate anxiety-like behavior: interaction with the opioid system. Behav Pharmacol 19: 716-723.

Zhu PJ, Lovinger DM (2005). Retrograde endocannabinoid signaling in a postsynaptic neuron/synaptic bouton preparation from basolateral amygdala. J Neurosci 25: 6199-6207.

Zhu W, Pan ZZ (2004). Synaptic properties and postsynaptic opioid effects in rat central amygdala neurons. Neuroscience 127: 871-879. 